\title{
Quimioterapia en pacientes con cáncer de pulmón de células no pequeñas
}

Winton T y col. N Engl J Med 2005; 352:2589-97

\section{Objetivo}

Determinar si la adyuvancia con cisplatino (CDDP) y vinorelbine (VNB) prolonga la sobrevida global en pacientes con estadíos precoces de cáncer de pulmón de células no pequeñas (CPCNP) que fueron resecados quirúrgicamente en forma completa

\section{Diseño}

Ensayo clínico prospectivo aleatorizado multicéntico abierto con un seguimiento medio de 5,2 años.

\section{Lugar}

Estudio multicéntrico canadiense y norteamericano.

\section{Pacientes}

Hombres $(n=314)$ y mujeres $(n=168)$ con CPCNP estadíos IB (45\%) y II (55\%) con resección quirúrgica completa; de 34 a 82 años de edad; con estadificación quirúrgica de mediastino (vaciamiento o muestreo de ganglios mayores a $1,5 \mathrm{~cm}$ ); sin carcinoma bronquioloalveolar lobar difuso ni multifocal; sin infección y sin deterioro clínicamente relevante de la función cardíaca, neurológica o psiquiátrica.

\section{Intervención}

Se aleatorizó a los pacientes para recibir quimioterapia postoperatoria versus observación. La quimioterapia se realizó con CDDP $50 \mathrm{mg} / \mathrm{m} 2$ los días uno y ocho cada 28 , durante cuatro ciclos; y VNB $25 \mathrm{mg} / \mathrm{m} 2$ semanal durante 16 semanas. Todos los pacientes recibieron ondansetron y la mayoría tambien corticoides.

\section{Medición de resultados principales}

El resultado principal fue la sobrevida global. El estudio fue diseñado con un poder del $80 \%$ para detectar una mejora de diez puntos porcentuales en la sobrevida global a partir de una estimada del $60 \%$ a tres años.

\section{Resultados principales}

La sobrevida global se prolongó significativamente con quimioterapia adyuvante a 94 meses contra 73 meses en el grupo observación (HR 0,69 IC95\%=0,52-0,91).

Se observó una ventaja de sobrevida de $15 \%$ a 5 años: $69 \%$ $($ IC95\%=62-75) para el grupo intervención y 54\% (IC95\%=48-61) en el grupo observación.

La quimioterapia redujo un $34,6 \%$ las recurrencias $\left(\mathrm{HR}^{*} 0,60\right.$ IC95\%=0,45-0,79). La sobrevida libre de recurrencia a cinco años fue $61 \%$ (IC95\% 54-68) en el grupo intervención contra $49 \%$ (IC95\% 42-55) en el grupo observación.

Respecto manifestaciones graves de toxicidad, $73 \%$ tuvieron neutropenia, $7 \%$ anemia, $1 \%$ trombocitopenia, $7 \%$ neutropenia febril, 2 $3 \%$ neurotoxicidad sensitivo-motora y $2 \%$ hipoacusia. Dos pacientes murieron por toxicidad relacionada al tratamiento. Un análisis de subgrupos no mostró una ventaja estadísticamente significativa en términos de sobrevida para los estadios IB.

\section{Conclusiones}

La quimioterapia adyuvante con CDDP y VNB prolongó la sobrevida global y la libre de enfermedad en pacientes operados de CPCNP con estadíos precoces; con un nivel de toxicidad aceptable aunque no despreciable.

Fuente de Financiamiento: $\mathrm{NCl}$ de Canadá, $\mathrm{NCl}$ de Estados Unidos y GlaxoSmithKline.

\section{Comentario}

Este estudio junto con el CALGB 9633, demuestran el beneficio de usar quimioterapia adyuvante en pacientes operados de estadíos precoces de CPCNP. Tres ensayos clínicos previos de adyuvancia en CPCNP habían arrojado resultados negativos (no hallaban diferencia estadísticamente significativa si se agregaba quimio con o sin radioterapia a pacientes operados con intención curativa en los que se lograba una resección completa). Un metaanálisis del British Medical Research Council', y el gran estudio IALT' ${ }^{2}$ encontraron una ventaja estadísticamente significativa en sobrevida pero el beneficio era tan marginal (5 y 4,1\%) que resultaba poco relevante desde el punto de vista clínico, por lo que en la práctica casi no se hacía adyuvancia en CPCNP si el resultado quirúrgico era satisfactorio; y en estadíos precoces, prácticamente se lo consideraba una contraindicación. Sin embargo, la sobrevida a cinco años de pacientes operados satisfactoriamente es 30 a $60 \%$, ya que los pacientes suelen fallecer por recaída local y a distancia.

En los estudios previos ${ }^{3.4}$ la mayoría de los pacientes fueron tratados con esquemas de primera generación, los trabajos incluían grupos de pacientes demasiado heterogéneos y los tratamientos combinaban también radioterapia, lo que dificultaba realizar la quimioterapia en tiempo y forma. Los últimos dos estudios ${ }^{5,6}$ que arrojaron ventajas de sobrevida similares, estadística y clínicamente relevantes, fueron realizados comparando grupos mas homogéneos de pacientes que fueron tratados solo con quimioterapia realizada con dos drogas de segunda generación (paclitaxel o vinorelbine mas cisplatino) que es el tratamiento estándar actual.

\section{Conclusiones del comentador}

Este estudio avala como estándar el uso de quimioterapia adyuvante en cáncer de pulmón para estadíos IB en adelante. No obstante, debido al estrecho rango terapéutico de las drogas en cuestión, cada caso debe ser evaluado individualmente y es el criterio clínico la primera condición para seleccionar adecuadamente a los pacientes que se puedan beneficiar de la intervención.

\section{Zenón Beguelin [ Servicio de Clínica Médica. Sección de Oncología Clínica. Hospital Italiano de Buenos Aires. ]}

Beguelín Z. Quimioterapia en pacientes con cáncer de pulmón de células no pequeñas. Evid. actual. páct. ambul. 9(2);39. Mar-Abr 2006. Comentado de: Winton T, Livingston R, Johnson D col. Vinorelbine plus Cisplatin vs. Observation in Resected Non-Small Cell Lung Cancer. N Engl J Med 2005; 352:2589-97

\section{Referencias}

1. Non-Small Cell Lung Cancer Collaborative Group. Chemotherapy in non-small cell lung cancer : a meta-analisis using updated data on individual patients from 52 randomised clinical trials. BMJ 1995;311:899-909.

2. The International Adjuvant Lung Cancer Trial Collaborative Group. Cisplatin-based adjuvant chemotherapy in patients with completely resected no-small cell lung cancer. N Engl J Med 2004;350:351-60.

3. Randomized trial of postoperative adjuvant therapy in patients with completely resected stage II or IIA non-small cell lung cancer. Keller SM, Adak S, WagnerH y col. . N Engl J Med 2000;343:1217-22.

4. Randomised study of adjuvant chemotherapy for completely resected stage I, II or IIIA non-small cell lung cancer. Scagliotti GV, Fossati R, Torri V y col. J Natl Cancer Inst 2003:95:1453-61.

5. Chemotherapy for non-samll cell lung cancer : the surgical setting of the Big Lung Trial. Waller D, Peake MD, Stephens RJ et al. Eur J Cardiothorac Surg 2004;26:173-82

6. Randomised clinical trial of adjuvant chemotherapy with paclitaxel and carboplatin following resection in Stage IB non-small cell lung cancer: Report of Cancer and Leukemia Group B (CALGB) Protocol 9633. J Clin Oncol 2004;22:suppl 14S:7019. 